\title{
NACIONALISMO COMO AUTO-REGENERAÇÄO: O CASO LOBATO
}

\section{Tadeu Chiarelli}

Pensar a identidade nacional no Brasil no campo da arte é pensar uma busca que já dura muitos anos. Uma busca que iria, pode-se dizer, de Araújo Porto-Alegre, no século passado, pensando uma história da arte brasileira e induzindo Victor Meirelles a pintar temas nacionais, até pelo menos Sérgio Romagnolo que, há quatro anos no MAM de Sāo Paulo, propos a exposiçāo "Arte Híbrida" onde - mais no catálogo e no debate que promoveu do que nas obras - dava prosseguimento a tal busca, interrogando-se sobre a identidade da arte brasileira.

Dentro desses dois marcos tão distantes no tempo, poderia citar vários artistas e intelectuais que também se preocuparam com csta questāo, uma questāo que muitas vezes impediu - e em alguns casos até hoje impede - fazer c pensar a arte no Brasil de maneira autónoma.

Desses indivíduos que se preocuparam com a busca de uma identidade nacional para a arte feita no país, uma arte que explicitasse de imediato sua procedencia geografica, escolhi estudar mais profundamente Monteiro Lobato. Em primeiro lugar, pelo fato de, a partir de minhas leituras iniciais da produçāo crítica do intelectual, ter percebido que o mesmo possuía um projeto de arte para o Brasil, um projeto nacionalista baseado na estética do naturalismo. Em scgundo lugar, pelo fato de Lobato ter mais tarde transformado esse projeto nacionalista de uma arte brasileira nuin projeto nacionalista de Brasil, atitude que, diga-se de passagem, muitas vezes lhe custou bastante caro.

Essas questóes, posso afírmar, sāo intcressantíssimas. Mas aqui gostaria de tentar me deter apenas no levantamento de uma das razōes 
que teriam levado Lobato a se tornar um dos símbolos do nacionalismo no pals.

Um dado significativo para se entender a base do nacionalismo lobatcano é o seu caráter regenerador. Quando Lobato surgiu na cena cultural paulistana, em plena I Grande Guerra, foi através do texto "Velha Praga".(1) Nesse artigo, se auto-definindo como a "voz do sertão", alertava os habitantes de São Paulo - segundo ele, embasbacados com os incendios que os alemaes causavam na Europa - para o horror dos incêndios que ocorriam no interior do Estado, causados pelo "caipira". Lobato propunha, portanto, que os brasileiros das cidades deixassem de se preocupar com o que se passava no exterior e prestassem mais atençāo ao país. Naquele momento estava querendo regenerar o brasileiro urbano, ou seja, transformar aquele ser "incaracterístico", voltado sempre para o que ocorria no exterior, num brasileiro de fato, preocupado com as questócs nacionais.

O seu projeto para a arte brasileira - explicitado já em 1915, quando publicou o artigo "A Caricatura no Brasil" (2) - tambem c um projeto de regeneraçāo. Preocupado com a supostumente exccssiva descaracterizaçāo da arte no país, Lobato conclamava os artistas locais a abandonarem a cópia servil dos valores da arte tradicional curopeia, a abandonarem as classes cultas brasileiras abestalhadas com tudo o que vinha sobrctudo da França, para mergulhar na captação da paisagem física e humana brasileiras, pois só assim, segundo ele, seria possível constituir uma arte tipicamente nacional.

Desde seu primeiro nacionalismo voltado para a regencração da arte brasileira, Lobato passaria, a partir do final da decada de 1910, a regeneração da população brasileira mais carente, através de sua campanha a favor do saneamento básico do pafs. Com o início dos anos 20 , suas atividades como editor revolucionário $\mathrm{e}$, mais tarde, suas campanhas a favor de uma sidcrurgia nacional e pela nacionalização do petróleo, demonstram que seu projeto nacionalista foi se expandindo até se caracterizar definitivamente como um projeto de regeneraçāo total do país, um projeto de redençāo da naçāo. Mcsmo sua atitude deliberada de constituir uma litcratura infantil se enquadra nesse projeto amplo.

Sem dúvida, uma série de circunstâncias particulares, mas também sociais, culturais e políticas, foi influenciando nessa expansăo do projeto nacionalista de Lobato, de sua circunscriçāo inicial ao campo da arte brasilejra, para outras áreas problemáticas da naçūo. Mas, rcstringindo este texto ao nascimento do discurso nacionalista de Lobato, gostaria de tentar esclarecer as circunstâncias de sua vida intelectual

1 - Unupks 11e. ed. Ed. Nacional, 1937.

2 - OEstado de S. Paulo, 27 e 28/01/1915. 
que o levaram (juntamente com outras de caráter político e cultural) a se preocupar em regencrar o Brasil.

A preocupaçāo de Lobato em regenerar a arte do país e de fazer a classe culta local - onde inseria os artistas - deixar de se preocupar com o que se produzia no exterior está ligada a um processo individual pelo qual passava o autor em meados da segunda década deste sćculo.

Naquele perfodo, Lobato estava tentando criar em si mesmo o sentimento de ser brasileiro que, até entāo, nunca o havia preocupado. Para o autor, engendrar uma nova arte, um novo artista e uma nova sociedade no Brasil era auto-engendrar-se. Quando cobrava dos artistas, e das camadas cultas da populaçāo, uma identificaçāo maior com a "verdadeira" nacionalidade, presente na natureza e na populaçāo agrária do pais, antes de a qualquer um, estava cobrando a si mesmo. Porque, ao contrário do que se pensa, Lobato nāo foi sempre um brasileiro. Encastelado numa formaçāo europcia, até por volta de 1915 era um estrangeiro exilado no Brasil.

Lobato, como a maioria dos jovens de sua classe social, formou-se intelectualmente em contato com a cultura e a literatura francesas. Em 1915, com 33 anos, depós que até os 25 anos podia contar nos dedos os poucos livros que lera em portugues.(3)

No período seguinte, quando ocorreu, digamos, a desinfecçāo da "sarna gálica", Lobato transferiu seu domićlio intelectual não para o Brasil, mas para Portugal, atraves do mergulho nos autores consagrados daquele país.

Foi a partir de 1907, em Portugal, ou melhor, na literatura "castiça "portuguesa, que Lobato encontrou sua identidade, seu lugar, sua pátria. Trabalhando em Areias - para ele uma cidade morta - , quando nāo estava debruçado sobre os clássicos portugueses estudando os mecanismos da língua, distrafa-se lendo semanários ingleses, numa recusa consciente em nāo se integrar à realidade à sua volta. Esta atitude pode ser percebida no trecho de uma carta que escreveu a Godofredo Rangel:

"Para neutralizar csta Areia scm apito tomci uma assinatura do Weekly Times... e com os pes na grade da sacada injetome de inglês, de pensamento inglês, de política inglcsa, cnquanto pela rua passam os bípedes que vāo mexcr a panclinha da política local..." (4)

3 - A Borea de Glogre 14! ed. Săo Paulo, Brasilicnse, 1972, p. 217.

4 - Idem. p. 122 
Ou seja, Lobato literalmente interpunha entre ele e a realidade de Areias (e do Brasil), a realidade curopéia, no caso, inglesa.

Apesar do interesse pela cultura inglesa, ela não obstrui a possibilidade dc se pensar Lobato nessa época como um portugues. Para o autor, o grande parâmetro intelectual cra Camilo Castelo Branco. Seu lugar, o espaço que pretendia ocupar, nāo ficava no Brasil, mas cm alguma aldeia minhota.

Esse processo de identificação com Castelo Branco e com o domínio que aquele escritor portugues possuía da língua portuguesa, fez com que Lobato desejasse sempre transferir-se literalmente para Portugal. Queria de fato ir (ou voltar, se pensamos que a pátria é a língua?) para a aldeia onde nasceu o escritor português $c$ apenas năo realizou tal sonho por causa da Guerra.

Sem poder assumir de fato o país ideal, devido ao conflito internacional, Lobato viu-se obrigado finalmente a deparar-se com o Brasil.

O primeiro elemento brasileiro que chamou sua atenção foi o camponés que passou a conhecer mais de perto entre 1913 c 1914, depois que herdou uma fazenda do avó no Vale do Paraíba.

De início, detestava o campones brasileiro, e nem o considerava de fato um ser racional. Porém, quando passou a compará-lo com o habitante de São Paulo (o de sua classe social), começou a perceber que o primeiro, apesar de ignorante, de viver uma vida quase animal, detinha uma série de qualidades e valores que o segundo (supostamente) nāo possuía.

Parece, então, que foi a partir do contato com o "caipira" que Lobato iniciou o processo de percepçáo dos supostos "defeitos de brasilidade" do homem urbano brasileiro.

Ora, era com o homem da cidade que Lobato de início se identificava. Uma identificação negativa porque era nele que via refletido seu próprio europeísmo, sua falta de brasilidade, sua condição socialmente superior ao camponês (não esquecer duas coisas: Lobato cra latifundiário na época; Lobato sempre teve um senso de justiça muito fortc). Percebendo-se como um privilegiado em relaçāo ao "caipira", percebendo-se como alguém que desprezava o país onde nasceu a favor de uma existência falsa e incaracterística, enquanto outros, apesar da "incultura" e da miséria, eram detentores de valores autonomos, Lobato repeliu a possibilidade de identificar-se plenamente com o homem da cidade e, consciente ou inconseientemente culpado, colocou-se ao lado do homem do campo.

Como Lobato administrou este processo? Inicialmente pela denúncia em seus artigos e críticas dos "Jefcitos" do homem da ci- 
dade: seu desenraizamento, seu europeísmo, seu descaso para com os valores nacionais, etc. "Defeitos" que na verdade eram dele. Características que o moldaram durante toda sua vida, até aquele momento.

Sem dúvida não e meu propósito reduzir as motivaçōes que levaram Lobato a se tornar nacionalista a um caso de complexo de culpa. No entanto, creio que este foi um fator decisivo para que o autor passasse a perceber e a considerar como seus os problemas do Brasil, já no início de sua trajetória como intelectual.

Nesse processo Lobato superou sua identificação com Camilo Castelo Branco, com a língua e com a cultura de Portugal, passando cada vez mais a se identificar com o Brasil e com a figura espoliada do camponés brasileiro, que desejava redimir.

Um índice flagrande deste seu processo é o livro Idéias de Jeca Tatu, de 1919 - balanço dessa primeira fase da carreira do intelcctual. Nele as idéias de Jeca Tatu são as idéias do autor. Jeca Tatu é Lobato ou o que o intelectual se propunha a ser a partir daqueles anos: Monteiro Lobato no indivíduo, paulista na espécie, brasileiro no géncro. 